Supplement of Geosci. Model Dev., 13, 6383-6423, 2020

https://doi.org/10.5194/gmd-13-6383-2020-supplement

(C) Author(s) 2020. This work is distributed under

the Creative Commons Attribution 4.0 License.

(c) (1)

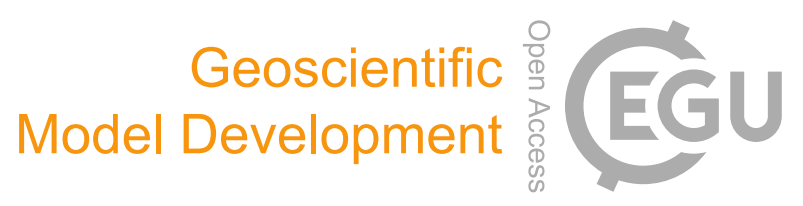

Supplement of

\title{
Description and evaluation of aerosol in UKESM1 and HadGEM3-GC3.1 CMIP6 historical simulations
}

Jane P. Mulcahy et al.

Correspondence to: Jane P. Mulcahy (jane.mulcahy@metoffice.gov.uk)

The copyright of individual parts of the supplement might differ from the CC BY 4.0 License. 

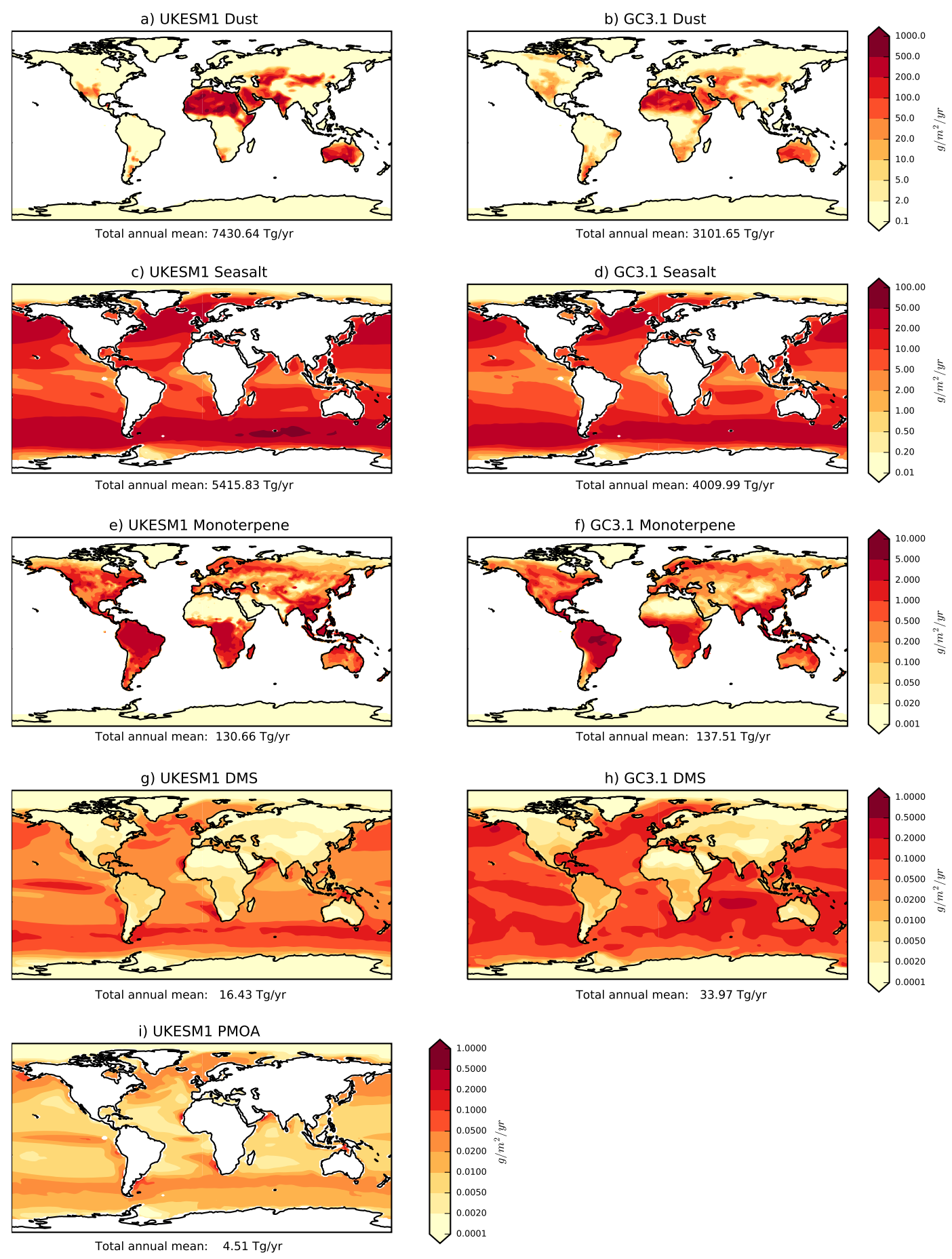

Figure S1: Annual mean emissions of (a,b) mineral dust, (c,d) sea-salt, (e,f) monoterpenes, (g,h) dimethyl sulfide (DMS) and (i) primary marine organic aerosol (PMOA) in (left) UKESM1 and (right) GC3.1. The annual emissions are calculated from an 18 year AMIP simulation covering the period 1980-1998. GC3.1 does not include a representation of PMOA. 
a) UKESM1 DJF

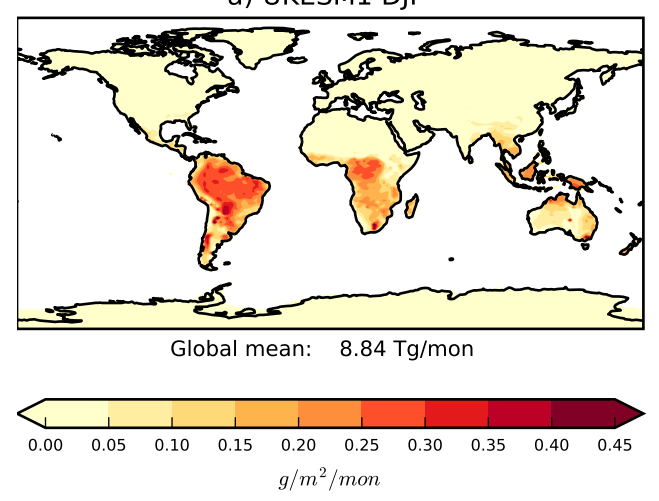

c) GC3.1 DJF

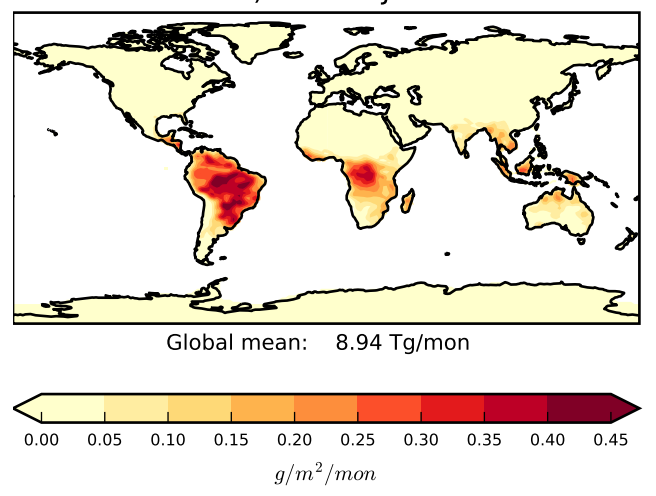

b) UKESM1 JJA
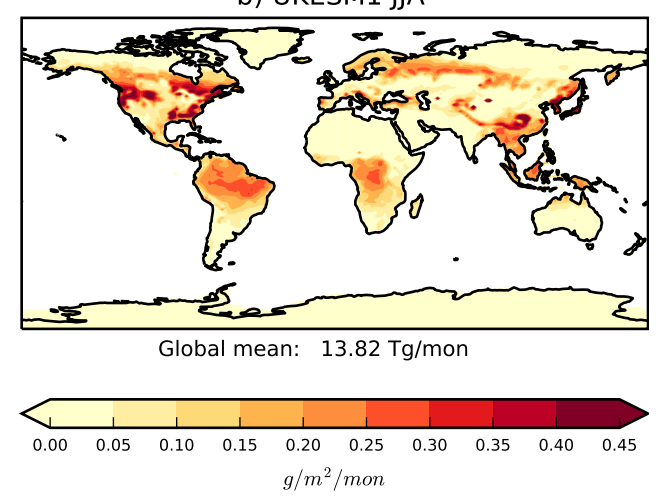

d) GC3.1 JJA
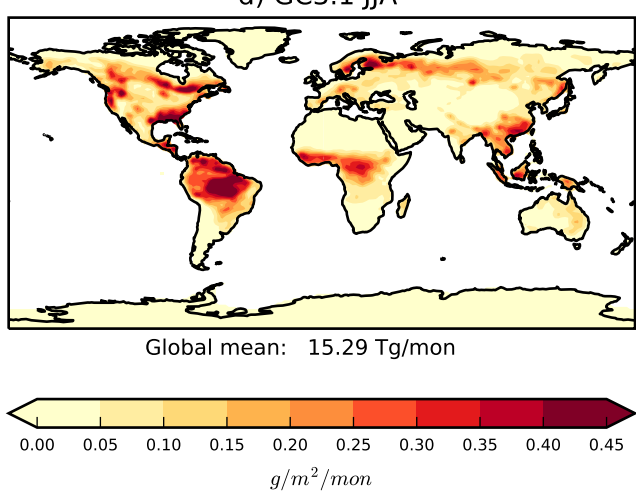

Figure S2: Monoterpene emissions from (a,b) UKESM1 and (c,d) GC3.1 for (left) DJF and (right) JJA. Emissions are calculated from an 18 year AMIP simulation covering the period 1981-1998 inclusive. 

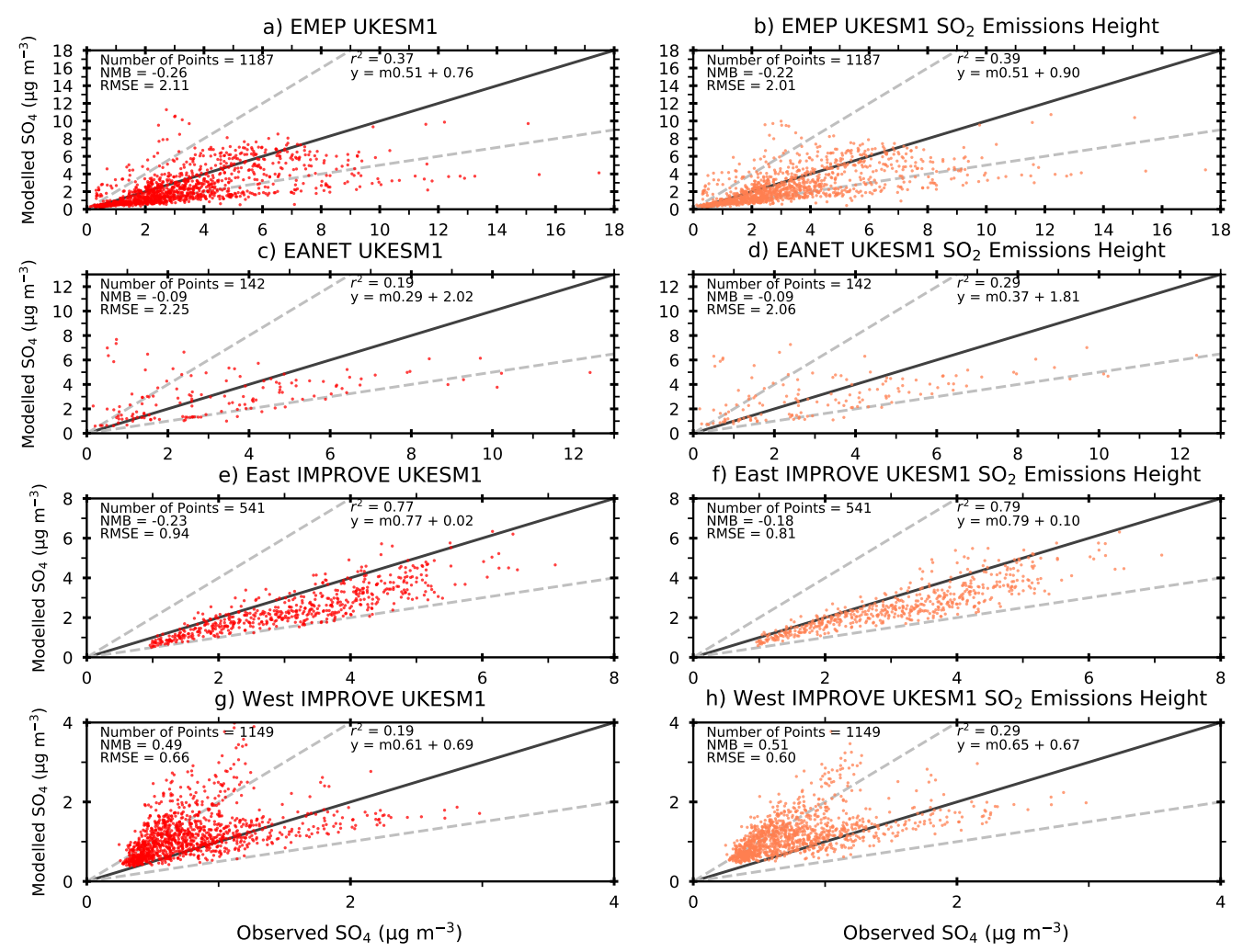

Figure S3: Comparison of simulated annual mean surface $\mathrm{SO}_{4}$ concentrations from (left column) UKESM1-AMIP and (right column) UKESM1-SO2 emission height sensitivity test against ground-based measurements from (a,b) EMEP (Europe), (c,d) EANET (East Asia), $(\mathrm{e}, \mathrm{f})$ IMPROVE (East North American sites) and (g,h) IMPROVE (West North American sites) networks. Observations and model data cover the years 1980 to 2010 for EMEP, 1988 to 2010 for IMPROVE and 2000 to 2010 for EANET. The 1:1 line is shown in solid black while factor of 2 differences are shown by the dashed grey lines. Normalised mean bias (NMB), root mean square error (RMSE), correlation coefficient $\left(r^{2}\right)$ and linear regression statistics are also included. The distribution of network stations is shown in Figure S4. UKESM1-SO2 emission height: A UKESM1-AMIP simulation in which the vertical distribution of anthropogenic $\mathrm{SO}_{2}$ emissions is split between the surface and $500 \mathrm{~m}$ consistent with GC3.1. 

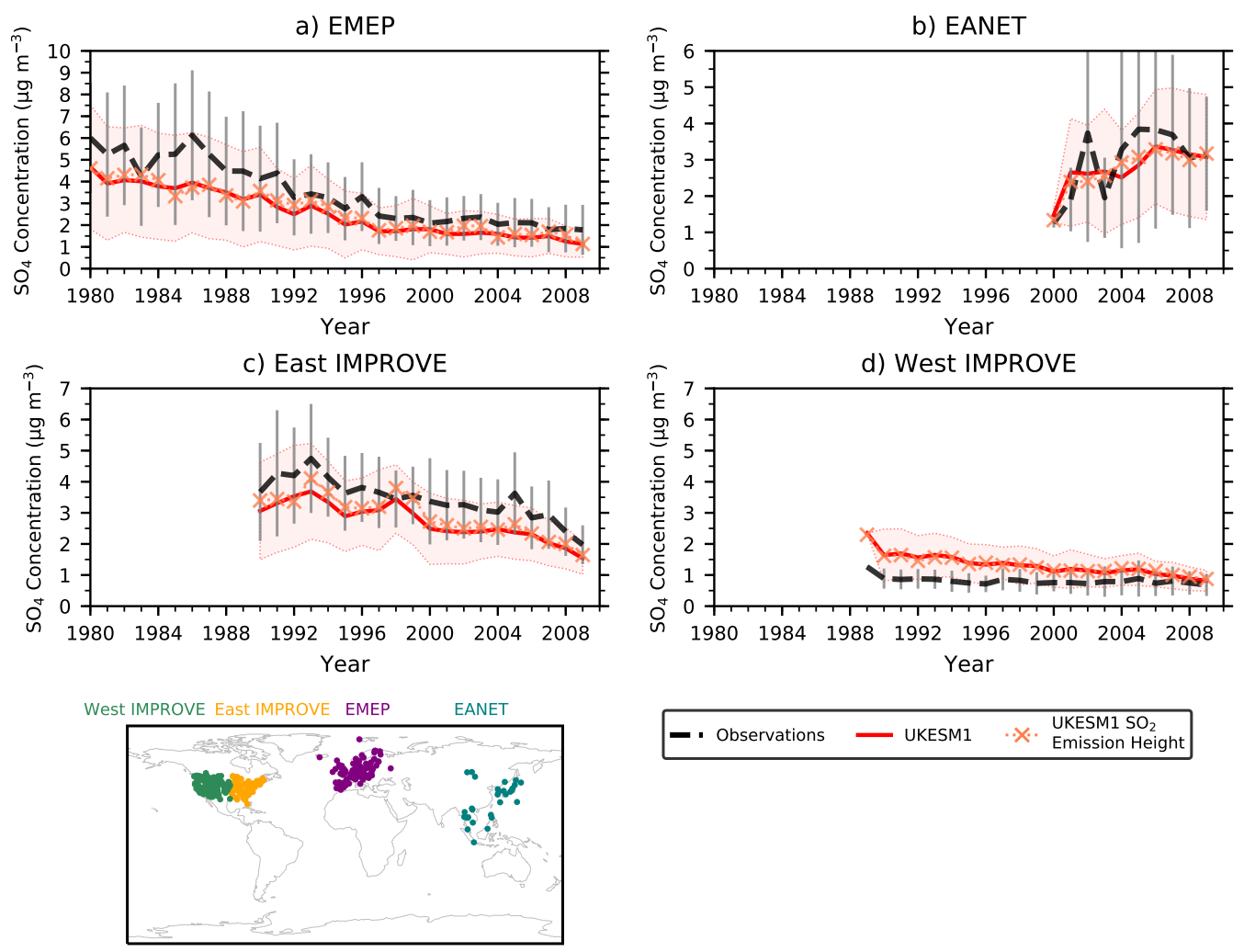

Figure S4: Time series of annual mean observed (dashed black lines) and simulated surface $\mathrm{SO}_{4}$ aerosol concentrations from UKESM1 (solid red line) and UKESM1-SO2 emission height sensitivity test (orange symbol). The data is averaged across all measurement locations in each network (EMEP, IMPROVE, EANET) for a particular year. Error bars and shaded areas show \pm 1 standard deviation of the observed and modelled annual mean values across all the measurement locations. The distribution of stations is shown in the bottom left panel. UKESM1-SO2 emission height: A UKESM1-AMIP simulation in which the vertical distribution of anthropogenic $\mathrm{SO}_{2}$ emissions is split between the surface and 500 m consistent with GC3.1. 